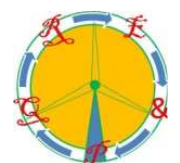

\title{
Comparative analysis of numerical models of plate-fin heat sinks with forced convection for thermoelectric energy generation
}

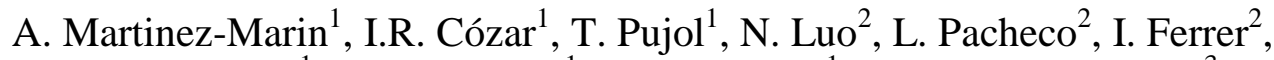 \\ J.R. Gonzalez ${ }^{1}$, A. Massaguer ${ }^{1}$, E. Massaguer ${ }^{1}$, Shazly A. Mohamed ${ }^{3}$ \\ ${ }^{1}$ Department of Mechanical Engineering and Industrial Construction, University of Girona, Campus Montilivi, 17003 \\ Girona (Spain) \\ ${ }^{2}$ Department of Electrical Engineering, Electronics and Automation, University of Girona, Campus Montilivi, 17003 \\ Girona (Spain) \\ ${ }^{3}$ Department of Electrical Engineering, Faculty of Engineering, South Valley University, Qena (Egypt) \\ Corresponding author: T. Pujol, e-mail: toni.pujol@udg.edu
}

\begin{abstract}
Plate-fin heat sinks under forced convection are economical dissipaters employed in a wide variety of sectors. These types of heat sinks are commonly used in power generation by means of commercial thermoelectric generator modules. The design of the heat sink is a key factor in these power generation systems since it greatly affects the efficiency of the direct conversion from heat into electrical energy. Here, we analyse several numerical models of plate-fin heat sinks under forced convection with and without air flow bypass. The predictions of both hydraulic and thermal parts of these models are compared with our own experimental data. Results reveal that Lindstedt and Karvinen model (2012) is the more accurate one, with discrepancies with respect to measurements below $12 \%$ for most of the cases studied.
\end{abstract}

Key words. Thermoelectricity, waste heat recovery, TEG.

\section{Introduction}

Thermoelectric generators (TEGs) are solid state devices that transform heat into electrical energy by means of the Seebeck effect. The simplicity and robustness of TEGs have increased the interest in their use as power generation systems for waste heat recovery. This technology is currently applied to power autonomous sensors, electronic devices in off-grid remote areas, etc. Great efforts are dedicated to employ them as massive power generators in industrial processes with large amounts of waste heat [1]. However, the efficiency of a TEG system highly depends on the design of its heat transfer system. The heat sink at its cold side is essential to obtain high heat transfer rates and, consequently, high power generation values. Therefore, an efficient design of the heat sink is key in the success of this technology.

Common heat sinks employed in thermoelectric generators are plate-fin ones. These are simple, economical and with reasonable values of thermal resistance, especially when a forced convection system is applied. Since plate-fin heat sinks are widely used in many applications, several researchers have proposed models to predict their hydraulic and thermal behaviours [2-8].
However, none of these models have been analysed in a system that contains a TEG. Here we perform this study in order to determine which of the formulations proposed better fit the experimental data and, therefore, can be used as a design tool to improve the efficiency of the whole power generation system.

\section{Experimental set up}

The experimental set up consists of three main parts: hydraulic, thermal and electrical. The hydraulic part consists of a steel rectangular tube $500 \mathrm{~mm}$ long with inner cross-section equal to $41 \times 41 \mathrm{~mm}$ (Fig. 1). We insert the plate-fin heat sinks analysed in the middle of this tube. There are two cones, with inserted honeycombs, at both ends of this tube in order to control the flow trajectories. A PVC pipe of $152 \mathrm{~mm}$ diameter is connected at one end of this cone. A DC powered fan is installed at the end of this PVC pipe to extract air from the system. Thus, the air into the experimental region is not blown in by the fan but suctioned by it. This method avoids the swirl effect that occurs at the exit of a fan and assures a more uniform flow behaviour in the test section.

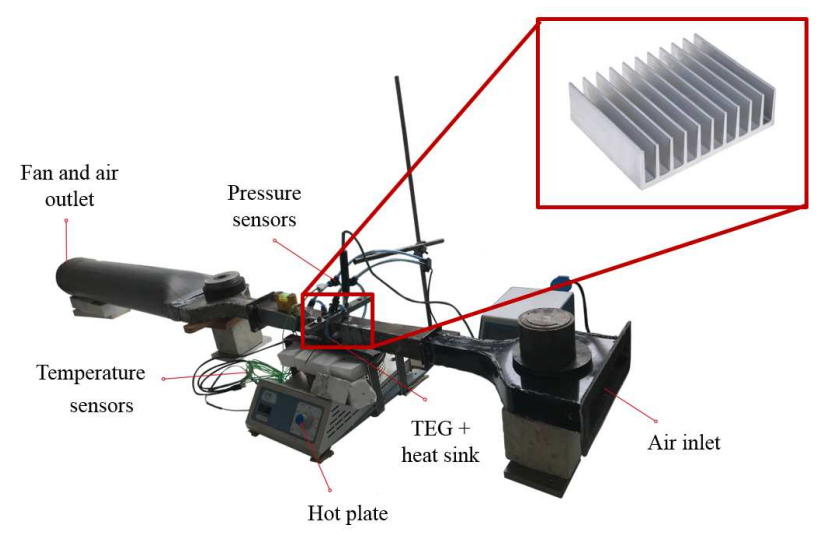

Fig. 1. The experimental set up.

Pressure difference between the inlet and the outlet of the plate-fin heat sink is measured by a Sensirion SDP610- 
125PA pressure sensor. The flow velocity is measured with a hot-wire anemometer Veloport 2.0 that was inserted at 10 different positions at the entrance cone. The air flow rate is calculated from the velocity data and, hence, the average velocity at the rectangular tube is deduced. The measurements were repeated three times in order to assure the repeatability of the experiment.

The thermal part consists of a hot plate (Combiplac, Selecta SA) whose temperature is controlled by a PID. There is a rectangular block of aluminium of dimensions 40x40 mm cross-section and $40 \mathrm{~mm}$ height. The end of this aluminium block is in contact with a ceramic slab 3 mm thick of known conductivity (Macor, Corning Inc.). The cold side of this ceramic slab is in contact with the hot side of a commercial thermoelectric generator (H-199-1406-L2, Crystal Ltd.). Finally, the hot side of the TEG is in contact with the base of the heat sink that is inserted within the rectangular tube (see Fig. 1). Temperatures at the interfaces of all materials, as well as that of the ambient air, are monitored with type $\mathrm{K}$ thermocouples, National Instruments modules and Labview. All these elements are clamped together in order to reach the recommended pressure on both TEG sides for its proper functioning.

Finally, the electrical part consists of a series connection of the TEG terminals with a rheostat. Current and voltages are monitored with National Instruments modules and read in Labview.

Two types of forced convection systems are here analysed: without bypass (heat sink occupies the entire tube crosssectional area) and with bypass (heat sink occupies a fraction of the tube cross-sectional area) (see Fig. 2). The non-bypass heat sink has 13 fins, $1.3 \mathrm{~mm}$ thick, with $\mathrm{H}=$ $36 \mathrm{~mm}$ and $\mathrm{W}=41 \mathrm{~mm}$. On the other hand, the bypass heat sink has 16 fins, $1 \mathrm{~mm}$ thick, with $\mathrm{H}=30 \mathrm{~mm}$ and $\mathrm{W}$ $=41 \mathrm{~mm}$.

\section{Numerical models}

A total of 7 numerical models of plate-fin heat sinks are analysed (Table I). Equations are not detailed here for brevity. They can be found in the references listed in Table I.

Table I. List of numerical models analysed.

\begin{tabular}{|c|c|c|c|c|}
\hline Ref. & Configuration & $\begin{array}{c}\text { Flow } \\
\text { regime }\end{array}$ & $\begin{array}{c}\text { Hydraulic } \\
\text { model }\end{array}$ & $\begin{array}{c}\text { Thermal } \\
\text { model }\end{array}$ \\
\hline$[2]$ & No bypass & Laminar & Yes & Yes \\
\hline$[3]$ & Bypass & Laminar & Yes & Yes \\
\hline$[4]$ & No bypass/Bypass & Laminar & Yes & No \\
\hline$[5]$ & No bypass & Laminar & Yes & No \\
\hline$[6]$ & No bypass & Any & Yes & Yes \\
\hline$[7]$ & No bypass & Laminar & Yes & No \\
\hline$[8]$ & Bypass & Laminar & Yes & Yes \\
\hline
\end{tabular}

Note that not all the models include the thermal terms nor are developed for both bypass and no bypass configurations.

Essentially, there are two objective variables: the pressure drop of the air flow $\Delta p$ through the heat sink and its thermal convective resistance $R_{c v}$. The pressure drop in all the models is calculated as a series pressure drops due to minor losses at the heat sink entrance, primary losses through the heat sink fins and minor losses at the heat sink exit. Bypass models determine the ratio of flow rate entering into the heat sink by assuming an equal pressure drop of the series one previously calculated and that obtained in the bypass region (no heat sink).

On the other hand, the thermal convective resistance in most of the models is obtained by assuming the common relationships with Nusselt and Prandtl numbers and the temperatures at both base plate and incoming air (the forced flow).
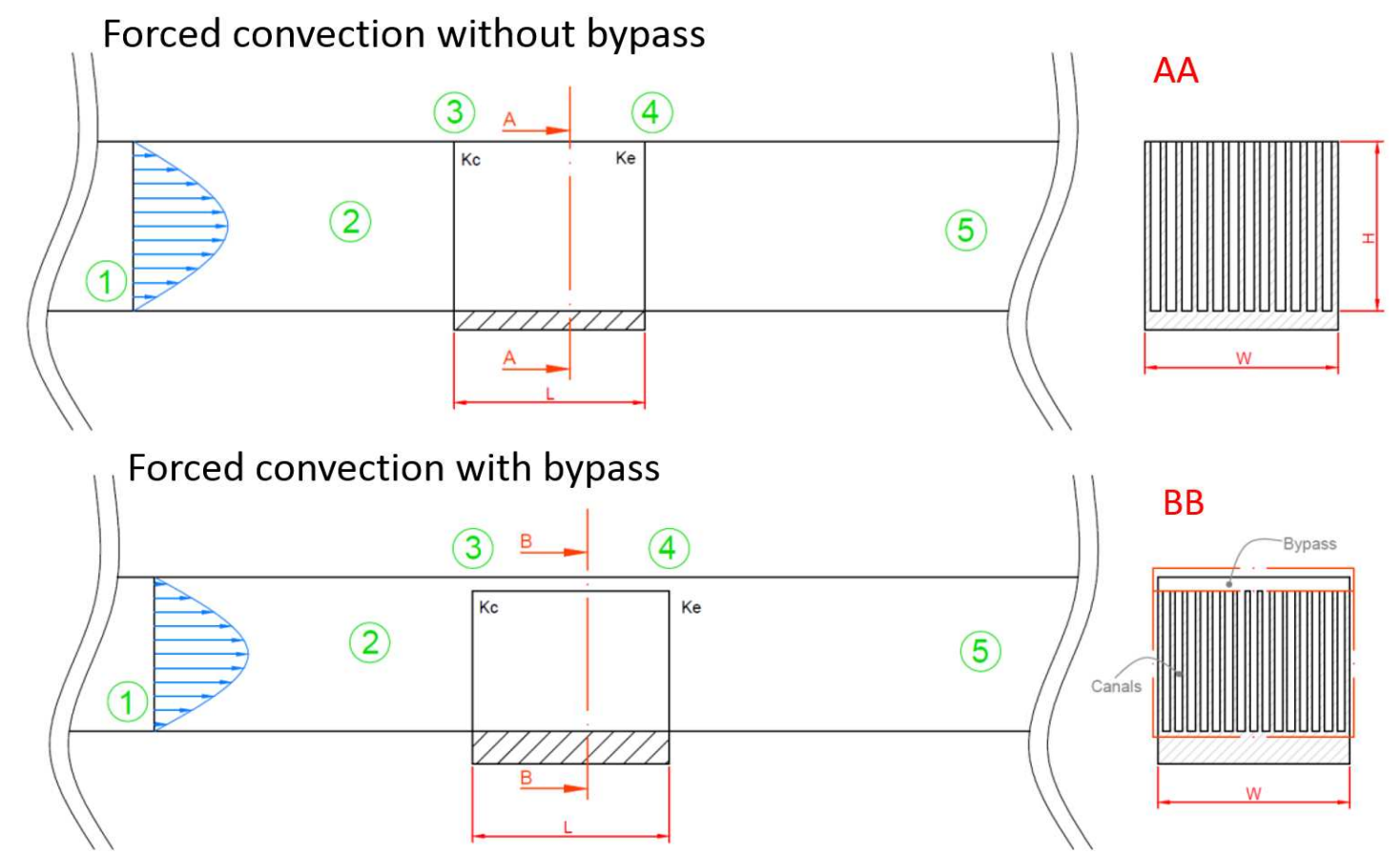

Fig. 2. Configurations analysed: forced convection without bypass and with bypass. 1) Incoming flow, 2) inlet, 3) contraction zone at the inlet (minor losses with coefficient $\mathrm{K}_{\mathrm{c}}$ ), 4) expansion zone at the exit (minor losses with coefficient $\mathrm{K}_{\mathrm{e}}$ ), 5) outlet. 


\section{Results}

Experimental data are obtained by fixing the hot plate temperature to $250^{\circ} \mathrm{C}$ and varying the voltage supply to the fan. This leads to different flow rates and, therefore, to different average flow velocities in the rectangular tube $v_{\infty}$.

Results for both hydraulic and thermal variables without bypass are shown in Fig. 3.
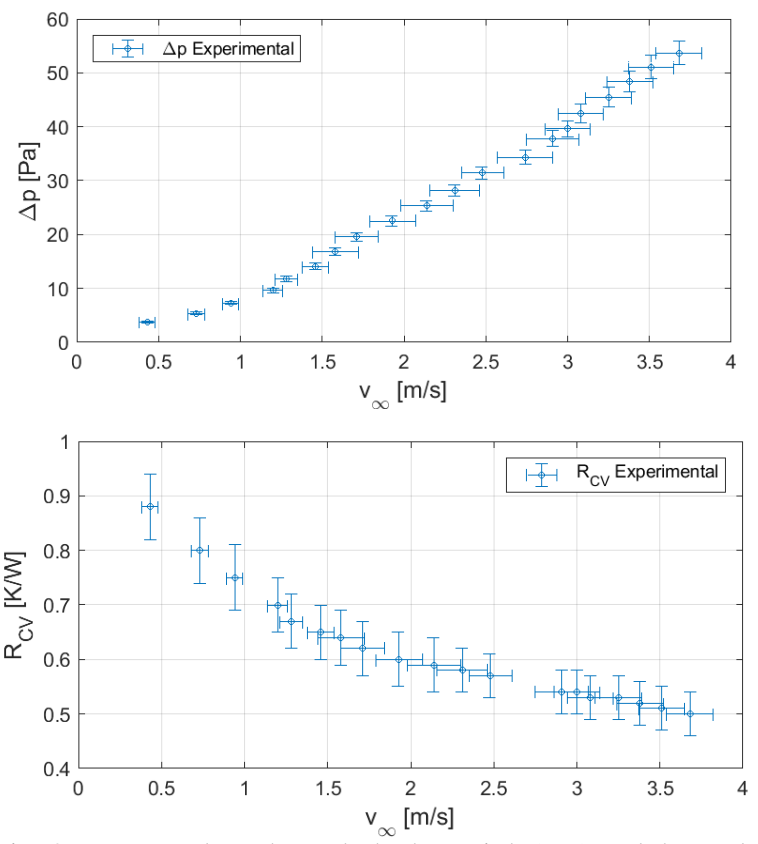

Fig. 3. Pressure drop through the heat sink (top) and thermal convective resistance (bottom) as a function of the air average velocity within the rectangular tube. No bypass case.

The air flow pressure drop through the heat sink behaves almost linearly as a function of the mean velocity at the rectangular tube. This is caused by the laminar regime observed in the flow between the channels of the dissipater, with $\mathrm{Re}<1800$ for the maximum flow rate available in our experiments. On the other hand, the thermal convective resistance values are similar to those reported by plate-fin heat sink manufacturers.

The comparison with numerical models is shown in Fig. 4 where the relative differences $(\%)$ between the modelled data and the experimental ones are reported. For the pressure drop, Lindstedt and Karvinen [6] and Kays and London [5] are the equations that provide a better fitting with the observations, especially in the high velocity range (with differences lower than $15 \%$ and $30 \%$, respectively). With respect to the thermal model, the Lindstedt and Karvinen one is the best one with very accurate predictions in a broad range of flow rates (differences lower than $7 \%$ for most of the cases being tested). We point out that Kays and London [5] do not provide a thermal model.

For the bypass case, the experimental data is shown in Fig. 5. Note that the pressure drop values were quite similar to those obtained in the non-bypass set up. This is due to the different heat sink type employed in the bypass test (see Section 2 and Fig. 2).

In comparison with the heat sink employed in the nonbypass case, the thermal convective resistance of the heat sink for the bypass case is smaller, especially at large flow rates. The flow in between the channels of the heat sink is also laminar.
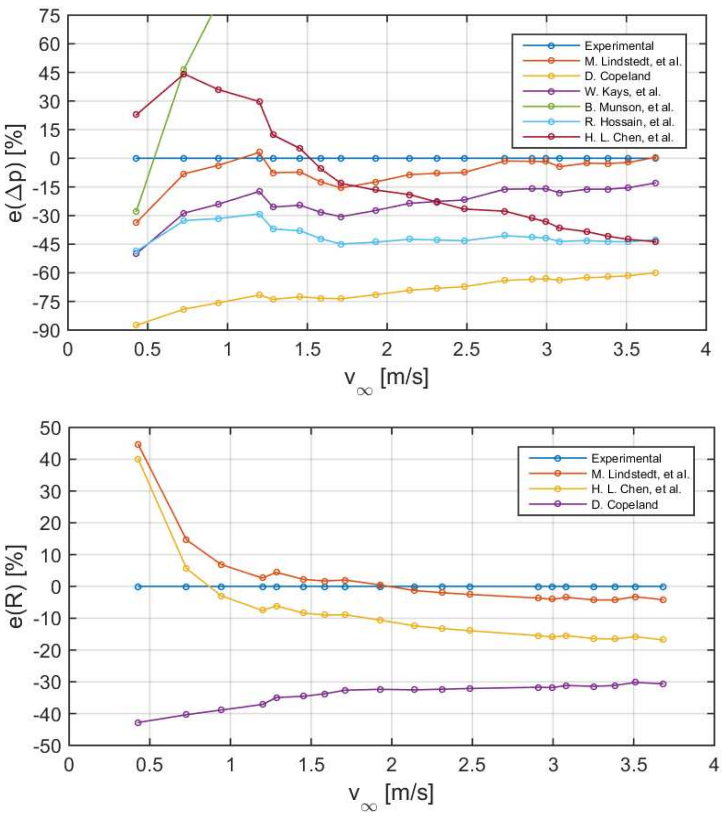

Fig. 4. Relative differences between modelled and experimental data of pressure drop through the heat sink (top) and thermal convective resistance (bottom) as a function of the air average velocity within the rectangular tube. No bypass case.
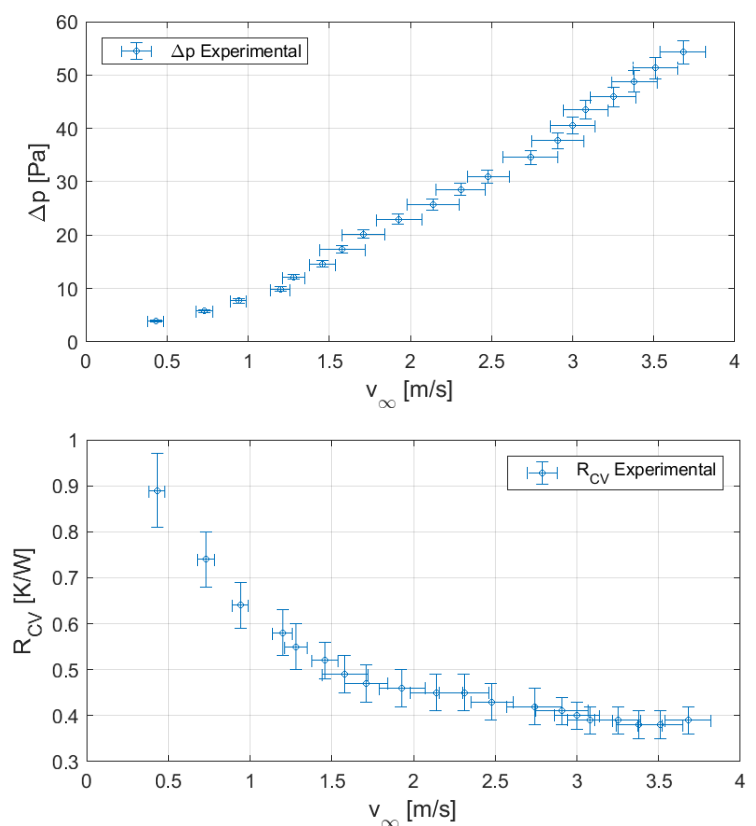

Fig. 5. Pressure drop through the heat sink (top) and thermal convective resistance (bottom) as a function of the air average velocity within the rectangular tube. Bypass case.

Although the Lindsted and Karvinen model [6] does not consider the possibility of a bypass, and in view of its good behaviour observed in the non-bypass case, we have generalized this model in order to include the bypass cases. It has been done by assuming equal pressure drop between points 2 and 5 in Fig. 2 when calculated from the flow through the bypass and from the flow through the heat sink. This condition allows us to determine the fraction of the incoming flow that moves through the heat sink. The comparison of the models with measurements for the bypass case is shown in Fig. 6. The Lindstedt and Karvinen [6] still provides the best 
accurate prediction, with deviations less than $10 \%$ in most of the cases.
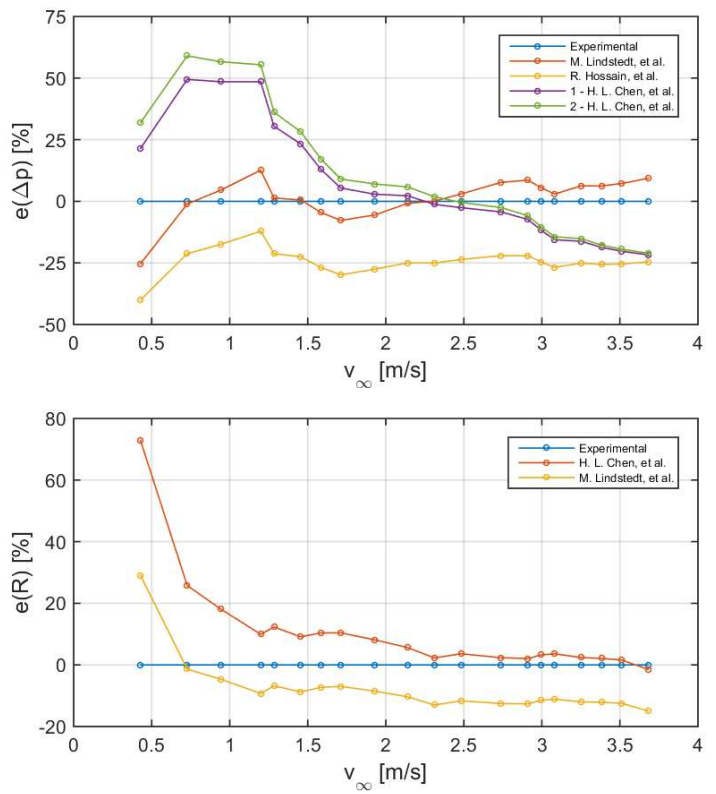

Fig. 6. Relative differences between modelled and experimental data of the pressure drop through the heat sink (top) and thermal convective resistance (bottom) as a function of the air average velocity within the rectangular tube. Bypass case.

Finally, we plot the experimental data of pressure loss and thermal convective resistance for both non-bypass (Fig. 7) and bypass (Fig. 8) cases adding the results of Lindstedt and Karvinen model [2]. The agreement is remarkable for both hydraulic and thermal variables although it diminishes at low air velocities, especially for the thermal convective resistance value.
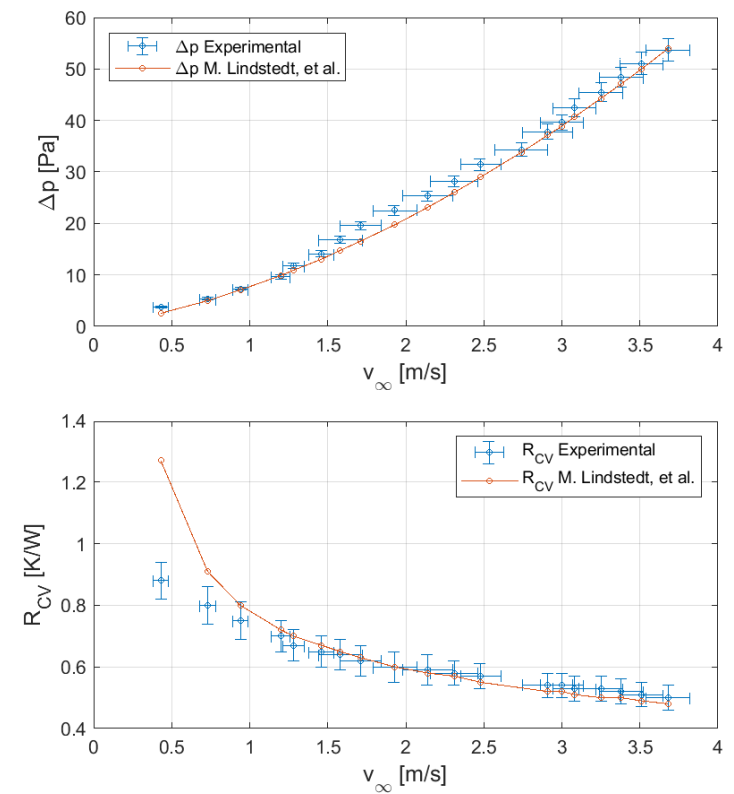

Fig. 7. Experimental data and predictions of the Lindstedt and Karvinen model [6] for the pressure drop through the heat sink (top) and thermal convective resistance (bottom) as a function of the air average velocity within the rectangular tube.
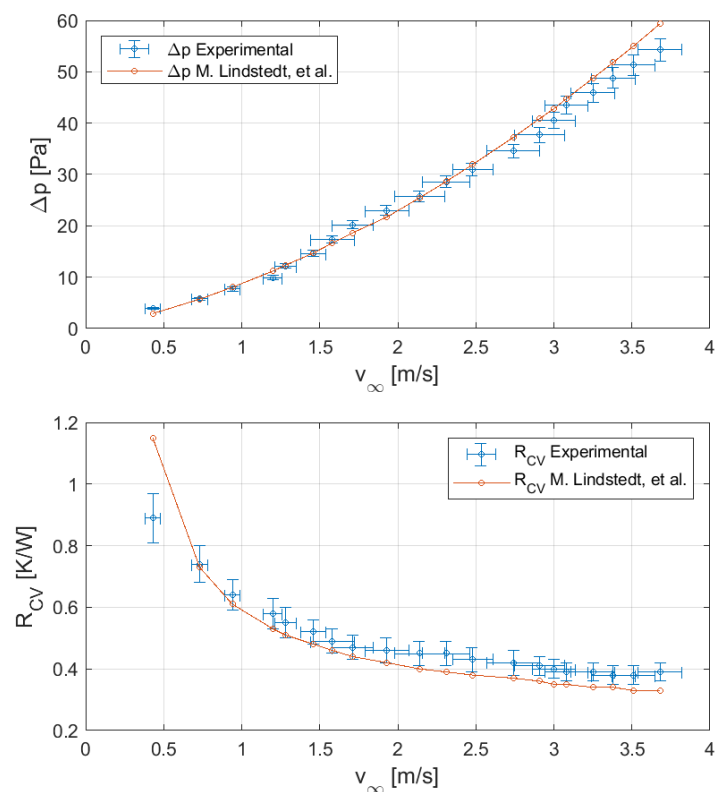

Fig. 8. Experimental data and predictions of the Lindstedt and Karvinen model [6] for the pressure drop through the heat sink (top) and thermal convective resistance (bottom) as a function of the air average velocity within the rectangular tube.

\section{Conclusion}

Several hydraulic and thermal models of plate fin heat sinks under forced convection have been analysed when applied in a thermoelectric power generation system. Model predictions have been compared with experimental data with and without bypass flow. The Lindstedt and Karvinen [2] model is the most accurate, with discrepancies below $12 \%$ in the majority of the values evaluated. It is recommended for the design of plate-fin heat sinks in thermoelectric power generation.

\section{Acknowledgement}

This work has been partially funded by the University of Girona through PONT2019/16.

\section{References}

[1] M. Comamala, T. Pujol, I.R. Cózar, E. Massaguer, A. Massaguer, "Power and Fuel Economy of a Radial Automotive Thermoelectric Generator: Experimental and Numerical Studies", Energies (2018). Vol. 11, 2720 pp. 1-21.

[2] H.-L. Chen, C.-C. Wang, "Analytical analysis and experimental verification of interleaved parallelogram heat sink", Applied Thermal Engineering (2017). Vol. 112, pp. 739729.

[3] D. Copeland, "Optimization of parallel plate heatsinks for forced convection", $16^{\text {th }}$ Annual IEEE Semiconductor Thermal Measurement and Management Symposium, IEEE (2000), pp. 266-272.

[4] R. Hossain, J.R. Culham, M.M. Yovanovich, "Influence of bypass on flow trhough plate fin heat sinks", $23^{\text {rd }}$ IEEE Semiconductor Thermal Measurement and Management Symposium, IEEE (2007), pp. 220-227.

[5] W.M. Kays, A.L. London, Compact heat exchangers, $3^{\text {rd }}$ Ed., McGraw-Hill, New York (1984), pp. 11-115.

[6] M. Lindstedt, R. Karvinen, "Optimization of plate fin arrays with laminar and turbulent forced convection", Journal of Physics: Conference Series (2012), Vol. 395, pp. 012059. 
[7] C.K. Loh, D.J. Chou, "Comparative analysis of heat sink pressure drop using different methodologies", $20^{\text {th }}$ IEEE Semiconductor Thermal Measurement and Management Symposium, IEEE (2004), pp. 148-153.

[8] B.R. Munson, D.F. Young, T.H. Okiishi, Fundamentals of fluid mechanics, $5^{\text {th }}$ Ed., John Wiley and Sons Inc, New York (2005), pp. 784. 